\title{
Coronary Arteriovenous Fistulae: A Review
}

\author{
Dimitris Challoumas, $\mathrm{BSC}^{1}$ Agamemnon Pericleous, $\mathrm{BSC}^{1}$ Inetzi A. Dimitrakaki, $\mathrm{MD}^{2}$ \\ Christos Danelatos, MD $^{3}$ Georgios Dimitrakakis, MD ${ }^{4}$
}

${ }^{1}$ School of Medicine, Cardiff University, Heath Park Campus, Cardiff,
United Kingdom
${ }^{2}$ Metropolitan Hospital of Athens, Neo Faliro, Athens, Greece
${ }^{3}$ Marousi, Athens, Greece
${ }^{4}$ Department of Cardiothoracic Surgery, University Hospital of Wales,
Cardiff, United Kingdom

Address for correspondence Dimitris Challoumas, BSc, School of Medicine, Cardiff University, Heath Park Campus, Cardiff CF14 4XW, United Kingdom (e-mail: challoumasd@cardiff.ac.uk).

Int J Angiol 2014;23:1-10.

\author{
Abstract \\ Keywords \\ - arteriovenous fistula \\ - cardiac surgery \\ - coronary artery \\ - fistula \\ - symptomatic \\ - cardiovascular disease \\ - cardiac \\ catheterization
}

Coronary arteriovenous fistulae are a coronary anomaly, presenting in $0.002 \%$ of the general population. Their etiology can be congenital or acquired. We present a review of recent literature related to their epidemiology, etiology, pathophysiology, clinical presentation, diagnostic approach, and therapeutic management.
Coronary arteriovenous fistulae (CAVF) are a major coronary anomaly, being present in $0.002 \%$ of the general population and was first described by Krause in $1865 .{ }^{1,2}$ The majority are congenital in origin, representing $0.4 \%$ of all cardiac malformations. ${ }^{3}$ These coronary artery anomalies involve one or more coronary arteries abnormally communicating with one of the cardiac chambers (coronary cameral fistulae) or the great vessels adjacent to the heart (coronary artery or arteriovenous fistulae). ${ }^{4}$

According to the classification by Ogden in 1970, CAVF belong to coronary arteries anomalies that also include anomalous pulmonary artery origins of the coronaries, anomalous aortic origins of the coronaries, congenital atresia of the left main coronary artery, coronary artery bridging, coronary aneurysms, and coronary stenosis. ${ }^{1}$

Coronary anomalies may be abnormalities of origin, distribution, or termination. CAVF are considered mainly to be termination abnormalities. ${ }^{5,6}$

Nomenclature is based upon a descriptive analysis of the vessel of origin and the chamber of termination. According to
Sakakibara et al, there are two types of angiographic classification: Type A-proximal type, where the proximal coronary segment is dilated to the origin of the fistula and the distal end is normal; and Type B-distal type, where the coronary artery is dilated over its entire length terminating as a fistula mainly into the right side of the heart (end-artery type) and the proximal coronary segment can or might have regular branches. ${ }^{6}$ Each one of these groups can be presented with different clinical signs and symptoms. ${ }^{6,7}$

\section{Epidemiology}

The incidence of coronary anomalies is 0.2 to $1.2 \%$ of the population. $^{6}$

CAVF are present in $0.002 \%$ of the general population and comprise $48.7 \%$ of all congenital coronary anomalies. ${ }^{8,9}$ They are the most common of hemodynamically significant coronary lesions. ${ }^{8-11}$

Among all pediatric coronary vasculature anomalies, approximately half of them are CAVF. ${ }^{12,13}$ 
2 Coronary Arteriovenous Fistulae Challoumas et al.

Table 1 Origin and drainage of fistulae

\begin{tabular}{|l|l|l|l|}
\hline Origin & Prevalence (\%) & Drainage & Prevalence (\%) \\
\hline LAD & $25-42$ & RA & $19-26$ \\
\hline RCA & $50-60$ & RV & $14-40$ \\
\hline Both & 5 & LA & $5-6$ \\
\hline Diagonal & 1.9 & LV & $2-19$ \\
\hline Marginal & 0.7 & PA & $15-20.2$ \\
\hline Circumflex & 18.3 & CS & 7 \\
\hline Single coronary & 3 & SCV & 1 \\
\hline
\end{tabular}

Abbreviations: CS, coronary sinus; LA, left atrium; LAD, left anterior descending; LV, left ventricle; PA, Pulmonary artery; RA, right atrium; RCA, right coronary artery; RV, right ventricle; SVC, superior vena cava.

Source: Adapted from Dodge-Khatami et al ${ }^{6}$.

Note: Low-pressure structures, such as the right chambers of the heart and the pulmonary artery are the most common sites of drainage. ${ }^{19}$

Complications owing to CAVF are present in $11 \%$ of the patients younger than 20 years and in $35 \%$ of the patients older than 20 years. ${ }^{12,13}$

Multiple fistulae are present in 10.7 to $16 \%$ of all CAVF with single fistulae being far more common occurring in up to $90 \%$ of the cases. ${ }^{3,8,14,15}$ CAVF are visualized in nearly $0.25 \%$ of the patients undergoing catheterization and there is no race or sex predilection. ${ }^{6,8,9,16,17}$ In other studies, CAVF have also been reported in approximately $0.3 \%$ of patients presented with congenital heart disease, $0.06 \%$ of children undergoing echocardiography, and 0.13 to $0.22 \%$ of adults undergoing coronary angiography. ${ }^{18}$

- Table 1 shows the percentage of fistulae originating from each one of the coronary arteries, and the percentage drained in each one of the cardiac chambers, great vessels, and coronary sinus. $^{6}$

\section{Etiology}

CAVF are primarily congenital, but they can be acquired in rare occasions. Acquired causes can be further subclassified into disease related, iatrogenic, and traumatic (-Table 2 ). ${ }^{19}$

\section{Morphology}

The arterial tree can communicate with a cardiac chamber or great vessel in the following two ways: either with the right side of the circulation (right atrium and its tributaries, coronary sinus, right ventricle, pulmonary artery) causing a leftto-right shunt; or with the left atrium or left ventricle causing an arterial runoff. The former is more frequent. ${ }^{20}$

The feeding artery of the fistula may drain from a coronary artery or one of its branches and it is usually dilated and tortuous. The more proximal the origin from the main coronary artery the more dilated the feeding artery tends to be and the more distal the origin the more tortuous it appears to be. Fistulae originating from the left coronary artery and draining into the left ventricle tend to be particularly tortuous, presenting a challenge for transcatheter closure (TCC). Finally, there may be multiple feeding arteries to a single drainage point, and multiple drainage sites may exist. ${ }^{20}$

\section{Pathophysiology}

Coronary "steal phenomenon" is believed to be the primary pathophysiological problem seen in CAVF without outflow obstruction. The mechanism is related to the runoff from the high-pressure coronary vasculature to a low-resistance receiving cavity (e.g., pulmonary vasculature) due to a diastolic pressure gradient. Eventually, there is a high risk of ischemia in the myocardium beyond the site of the origin of the fistula, which is most frequently evident in association with increased myocardial oxygen demand during exercise or activity. ${ }^{3}$ Normal thin-walled vessels exist at the arteriolar level that may drain into the heart (arteriosinusoidal vessels) and venous communications (thebesian veins) to the right atrium. These small vessels do not steal significant nutrient flow and do not constitute fistulous connections.

Fistulae can be large ( $>250 \mathrm{~mm}$ ) and dilated or ectatic, and they tend to enlarge over time. ${ }^{21}$

Table 2 Causes and associations of coronary arteriovenous fistulae

\begin{tabular}{|l|l|}
\hline Congenital & $\begin{array}{l}\text { Embryonic } \\
\text { Multiple; systemic hemangioma }\end{array}$ \\
\hline Acquired & Disease related \\
& Acute myocardial infarction \\
& Hypertrophic cardiomyopathy \\
& Dilated cardiomyopathy \\
& Tumor \\
& latrogenic \\
& Percutaneous coronaty balloon angioplasty \\
& Coronary Artery Bypass Grafting \\
& Cardiac transplant \\
& Permanent pacemaker placement \\
& Closed-chest ablation for accessory pathway \\
& Endomyocardial biopsy \\
& Traumatic \\
& Penetrating and nonpenetrating trauma \\
\hline
\end{tabular}

Congenital and Acquired causes. The acquired etiology is subcategorized into disease-related, iatrogenic and traumatic.

Source: Adapted from Angelini et al. ${ }^{19}$ 
On the contrary, Angelini et al have concluded against this pathophysiological mechanism as a cause of critical ischemia because of the following reasons: (1) only a few coronary fistulae cause chest pain or reversible ischemia during functional testing, (2) at the fistulous site, there is favorable readjustment of the nutrient fistulous flow ratio following exercise, despite the vasodilatation of the nutrient branches, and (3) under resting conditions, a myocardial infarction, resting chest pain, or hibernation would only be caused secondary to a significant coronary steal phenomenon; something that has not yet been reported. ${ }^{19,22}$

The possible complications of CAVF are coronary artery dilatation, aneurysm formation, intimal ulceration, medial degeneration, intimal rupture, atherosclerotic deposition, calcification, side-branch obstruction, mural thrombosis, and rupture. ${ }^{3}$ A left-to-right shunt exists in over $90 \%$ of cases. $^{16}$

\section{Clinical Presentation}

It is commonly believed that the lesion is incidentally detected on routine examination or during coronary angiography. ${ }^{23}$ Small fistulae are asymptomatic but in the large ones symptoms may be present before 20 years of age. ${ }^{24}$ In fact, large fistulae have been seen to be associated with presentation of signs of congestive heart failure, especially in infancy. ${ }^{18}$

Generally, the symptoms develop depending on the amount of the left-to-right shunt or the presence of coronary steal phenomenon of the fistulae, which usually present in young adults with angina (3-7\%), exertional dyspnoea (60\%), endocarditis in the fistula (20\%), syncope, palpitations, myocardial ischemia and infarction, and manifest in older adults with congestive heart failure (19\%), atherosclerosis, and cardiac arrhythmias. ${ }^{25,26}$

Angina pectoris occurs as a result of the coronary "steal phenomenon" where there is blood shunting and perfusion away from the myocardium. This may be a cause for the development of a coronary artery aneurysmal change. 25,26

Symptoms of congestive heart failure may result when the fistula drains into the right system resulting in congestion and pulmonary hypertension. ${ }^{11}$ Such symptoms are common, particularly in neonates and infants who present with large fistulae that result in a large volume shunt. ${ }^{18}$ The fistula may rupture spontaneously, causing hemopericardium and cardiac tamponade. ${ }^{9}$ Rarely, sudden death can occur, especially in young patients, as in the case of a 7-year-old patient who had acute pulmonary edema after anesthesia. ${ }^{27,28}$

The predominant physical finding is a continuous murmur, representing the systolic-diastolic flow in large fistulae. ${ }^{29,30}$

CAVF, especially in asymptomatic patients, are usually suspected when a murmur is detected. Pediatric patients with fistulae are often brought into attention following presentation of an unexplained murmur. ${ }^{18}$ The murmur is heard the loudest on the chest wall depending on where the fistula enters the heart, its character is soft at a grade of $2 / 6$ to $4 / 6$; it is also continuous and tends to be crescendo- decrescendo, in both systole and diastole. It is however louder in diastole. ${ }^{4}$

A smaller percentage of pediatric patients tend to be asymptomatic, unlike adults. Associated congenital cardiovascular anomalies have been reported in the literature in 5 to $30 \%$ of cases such as atrial septal defect, Tetralogy of Fallot, ventricular septal defect, and patent ductus arteriosus. 3,31

\section{Diagnostic Approach}

Physical examination is very important as the signs mentioned above in Section 5 will indicate further investigation with imaging.

Angelini suggested a very useful screening and treatment guideline (-Fig. 1). ${ }^{32}$ According to this approach, a nonathlete with mild symptoms should initially be investigated with an electrocardiograph (ECG) and a chest X-ray (CXR). Should these be negative, no additional investigations are required and if positive, an echocardiogram (Echo), a treadmill test (TMT), and heart catheterization with intravascular ultrasound scan (IVUS) should follow. In an athlete with mild symptoms, initial approach should include ECG, CXR, Echo, TMT, and transthoracic echocardiography (TTE) that would dictate whether only clinical follow-up is needed (if negative) or catheterization with IVUS (if positive) is needed. If the latter is performed and shows intramural changes with severe narrowing, endovascular intervention, or surgery should be considered, otherwise medical therapy and follow-up would suffice. ${ }^{32}$

In the case of severe clinical symptoms, independent of the athletic background of the patient, ECG, TMT, TTE, and CXR should first be performed and followed by cardiac catheterization with IVUS. ${ }^{32}$

\section{Specific Diagnostic Investigations}

\section{ECG}

The ECG might show the left ventricular volume overload and sometimes ischemic changes, but it is very rarely useful in the primary diagnostic approach of CAVF. ${ }^{20}$

\section{CXR}

A CXR might indicate cardiomegaly when there is a large leftto-right shunt but is otherwise normal. ${ }^{20}$

\section{Echocardiography}

Two-dimensional (2D) echos can show left atrial and left ventricular enlargement or decreased regional or global dysfunction. It is not however suitable for the functional evaluation of the fistulae. ${ }^{32}$

Transesophageal echocardiography (TOE) may also be used to obtain information about the fistula. Therefore, intraoperative TOE can greatly contribute to the facilitation of surgical treatment by identifying the origin, the draining points for the fistula, the quantification of valve regurgitation, and finally the efficacy of CAVF obliteration. ${ }^{33,34}$

CAVF should normally be suspected when 2D imaging of the main coronary arteries in the parasternal short axis view shows one artery dilated and the other one of normal size. ${ }^{23}$ 


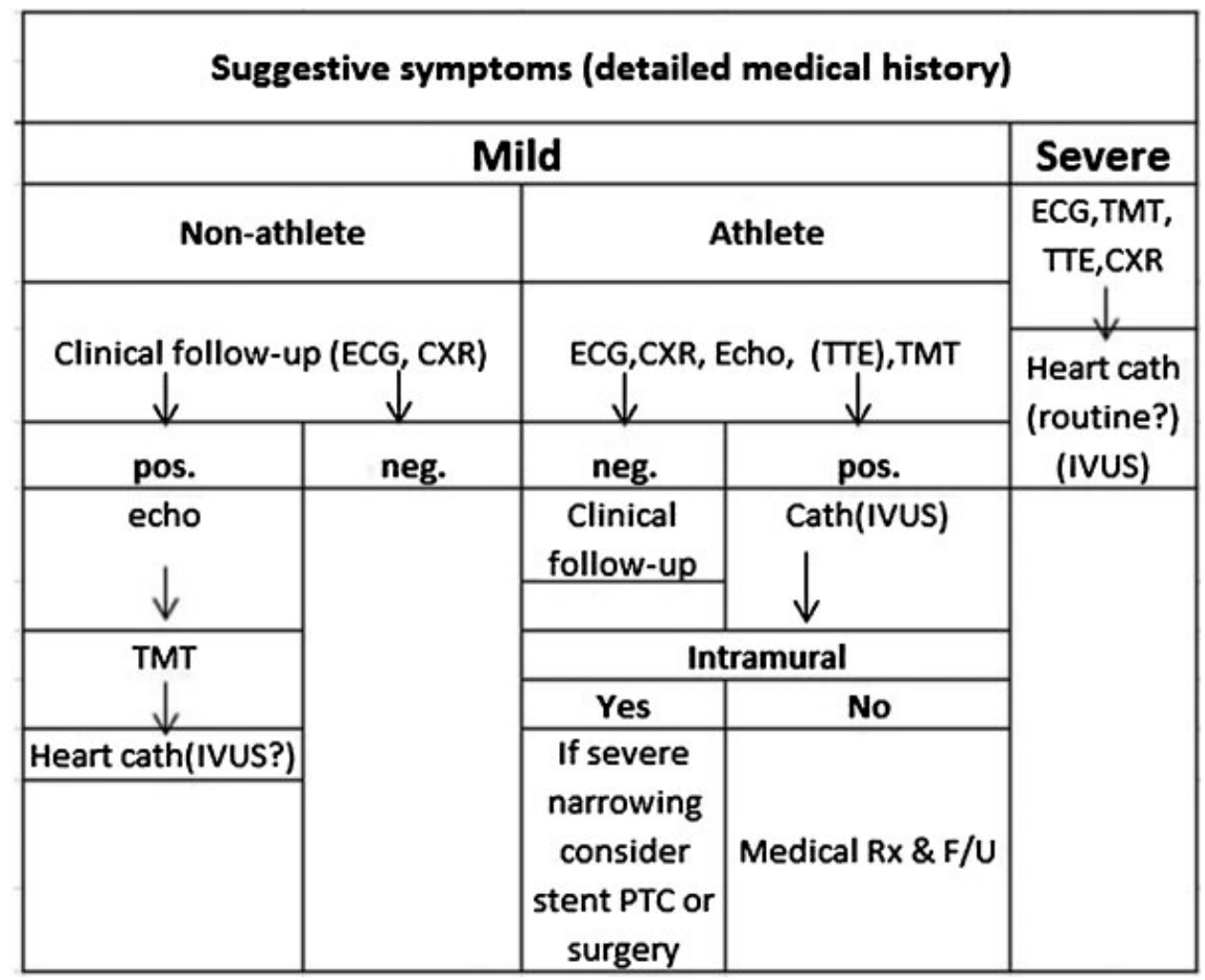

Fig. 1 Proposed diagnostic protocol for adult patients who are at risk for coronary artery anomalies. CXR, chest X-ray; ECG, electrocardiogram; echo, echocardiogram; F/U, follow-up; IVUS, intravascular ultrasound; neg., negative; pos., positive; PTCA, percutaneous transluminal coronary angioplasty; Rx, treatment; TMT, treadmill test; TTE, transthoracic echocardiogram. (Adapted from Angelini.) ${ }^{32}$

\section{Coronary Artery Angiography}

Angiography is the main diagnostic technique for the precise diagnosis of the fistulae. Cardiac catheterization provides the hemodynamic evaluation of the fistula and remains the modality of choice for defining coronary artery patterns for structure and flow. It can be used for therapeutic embolization with occlusive oils and devices as well. ${ }^{35}$

Angiography provides the most detailed anatomy of the fistula giving information about the size, the course, the origin, the presence of any stenosis, and the drainage site, as well as it helps to exclude various anomalies and defects, including but not limited to patent ductus arteriosus, ventricular septal defects with aortic incompetence, and arteriovenous fistulae in the lungs or chest wall. ${ }^{35}$

However, in some cases, origin and relation of the CAVF to adjacent structures may be difficult to determine, thus noninvasive techniques may be used as adjunct.

\section{Multidetector Computed Tomography}

Multidetector computed tomography (MDCT) is superior to echocardiography in overweight patients, where they allow excellent anatomical delineation, in contrast to echocardiography. The presence or absence of obstruction can be determined with MDCT, and therefore, the likelihood of a coronary steal presentation (-Figs. 2 and 3). A contrast opacification into the receiving chamber/vessel is useful in confirming the CAVF entry site and patency of the shunt. ${ }^{36-38}$

\section{Additional Workup}

Magnetic Resonance Imaging (MRI)

MRI may help in the confirmation of the diagnosis. It may reveal the detailed anatomy of the CAVF and can be used as an adjuvant noninvasive method in their investigation. ${ }^{39}$

\section{Myocardial Perfusion Scan}

Myocardial perfusion scan can be a useful tool in the assessment of myocardial ischemia related to the CAVF. The radionuclide examinations in general, can dictate whether invasive treatment is required or not. If the patient has limited myocardial ischemia territory ( $<10 \%$ left ventricular surface area) and is asymptomatic pharmacotherapy is the first-line treatment. ${ }^{40}$

\section{Intracoronary Doppler Ultrasound Scan}

Intravascular Doppler ultrasonography may provide additional information about the pathophysiology of the fistula. ${ }^{41}$

\section{Management}

There is general agreement that symptomatic patients should be treated. ${ }^{3}$ According to the American College of Cardiology/ American Heart Association (ACC/AHA) guidelines, "percutaneous or surgical closure is a Class I recommendation for large fistulae regardless of symptoms and for small- to moderatesize fistulae with evidence of myocardial ischemia, 


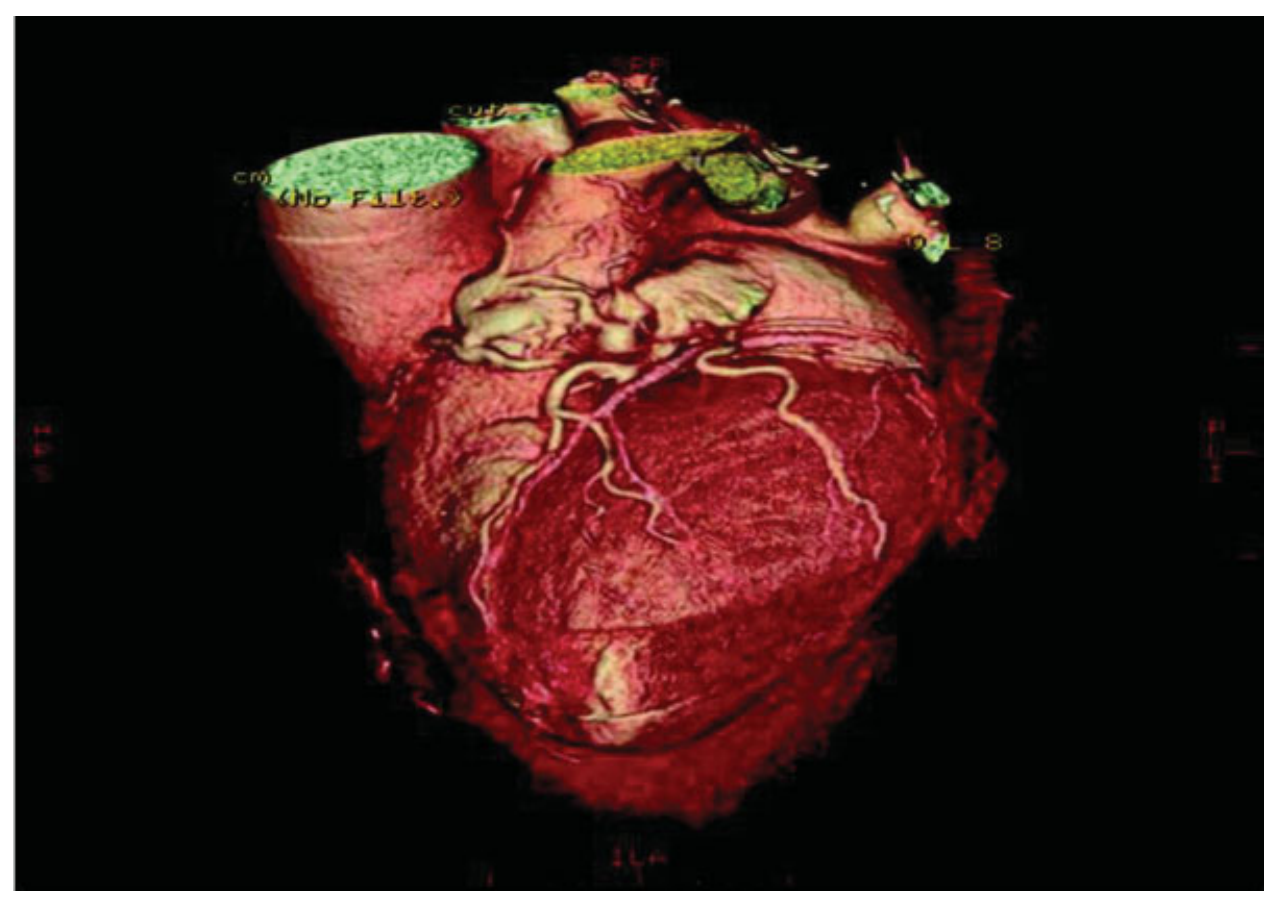

Fig. 2 Reformatted computed tomography scan showing the involvement of the right coronary, the left anterior descending and the circumflex coronary arteries as well as the vascular "lakes"3. Reproduced by Dimitrakakis G, Von Oppell U, Luckraz H, Groves P. Surgical repair of triple coronary-pulmonary artery fistulae with associated atrial septal defect and aortic valve regurgitation. Interact Cardiovasc Thorac Surg 2008;7(5):933-934

arrhythmia, ventricular dysfunction, ventricular enlargement, or endarteritis". ${ }^{42}$

Some authors recommend closure of CAVF even in asymptomatic patients to prevent fistula-related complications. ${ }^{6}$ With regard to children, and in particular those that are more than 3 to 5 years of age, elective closure of any clinically apparent fistula should be performed, even if the patient remains asymptomatic. ${ }^{18} \mathrm{~A}$ very important complication that has been reported in children is late stenosis, secondary to intimal hyperplasia, that increases the risk for myocardial infarction later in life. ${ }^{18}$

Taking into consideration that spontaneous closure of the fistula secondary to spontaneous thrombosis has been reported in rare occasions ( $1-2 \%$ of cases), especially in small fistulae in infants younger than 2 years, then the continuous follow-up of these patients is of paramount importance. ${ }^{31}$

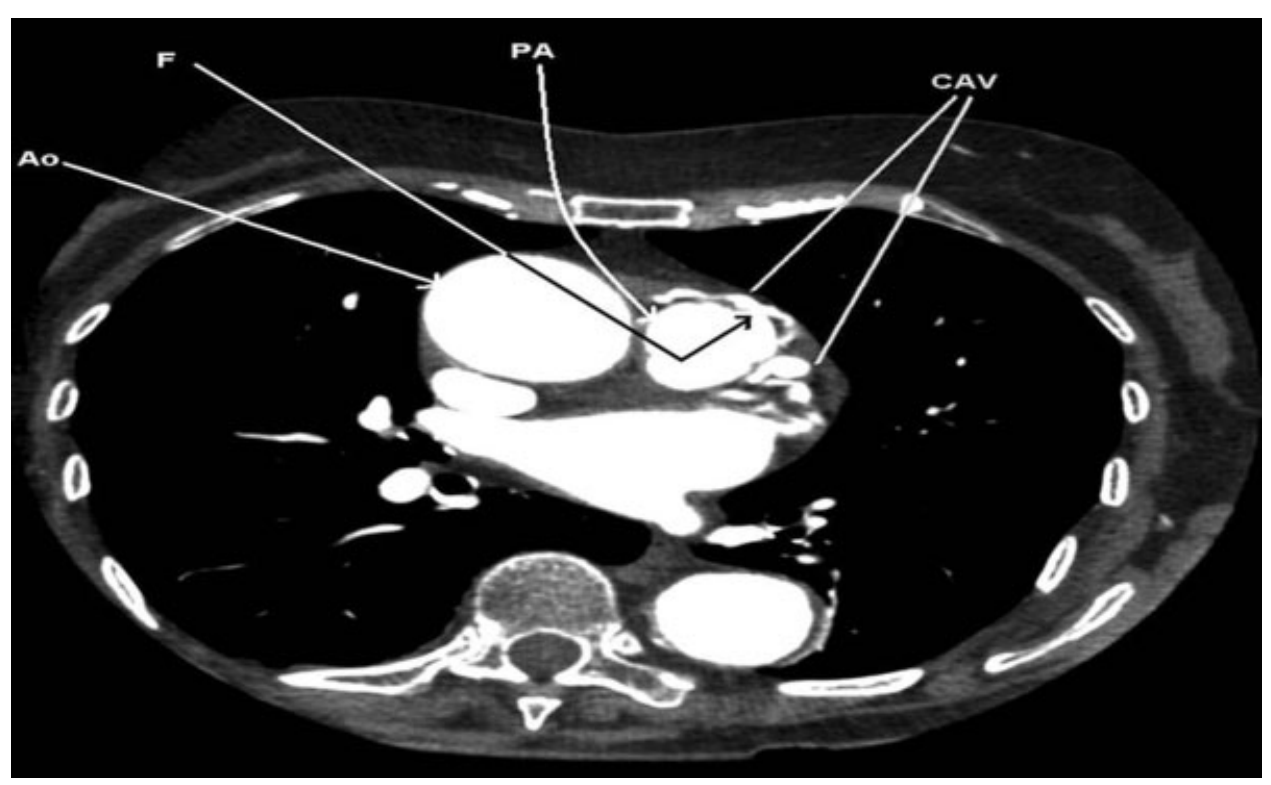

Fig. 3 Transverse computed tomography scan thorax with contrast showing the coronary arterio-venous malformations (CAV) and the fistulous (F) opening within the pulmonary artery. ${ }^{3} \mathrm{AO}$, aorta; PA, pulmonary artery. Reproduced by Dimitrakakis G, Von Oppell U, Luckraz H, Groves P. Surgical repair of triple coronary-pulmonary artery fistulae with associated atrial septal defect and aortic valve regurgitation. Interact Cardiovasc Thorac Surg 2008;7(5):933-934 
In addition, closure of fistulae that arise in the proximal segment of the coronary vessel is highly recommended as this type of fistulae is more likely to become aneurysmal with a high possibility of rupture. ${ }^{18}$

\section{Therapeutic Modalities}

\section{Transcatheter Closure}

TCC avoids surgical intervention and all related complications including surgical stress, bleeding, infections, events related to inflammatory response due to cardiopulmonary bypass, wound healing problems, and general anesthesia adverse events . The TCC technique is indicated when the anatomy of the fistula is favorable for this treatment (e.g., nontortuous vessel, the fistula should be unique with distal narrowing to avoid embolism to the drainage site, distal portion of the fistula should be accessible with the closure device, and there should be no concomitant cardiac disorders requiring additional surgical intervention). ${ }^{10,36}$

Vessel tortuosity and lumen caliber appear to be significant limitations in occlusion device delivery, as reported in the small study by Collins et al. ${ }^{43}$

TCC was added to the therapeutic approach of fistulae in 1983, after the first successful management of a CAVF with TCC by Reidy and his colleagues on a patient with severe angina. During the treatment, simultaneously coronary angioplasty was performed for critical stenosis of the anterior descending coronary artery plus transcatheter occlusion by detachable balloon in the large distal circumflex coronary artery for a coronary to bronchial fistula. ${ }^{13,44}$

The recent introduction of advanced interventional devices has greatly contributed to the increasing use of TCC for the treatment of CAVF. ${ }^{13,45}$ The choice of device and technique depends on the anatomic characteristics of the CAVF as well as the age and the size of the patient, the catheter size that can be used in the patient, the size of the occluded vessel, and the tortuosity of the catheter course to reach the intended point of occlusion. ${ }^{20}$ Gianturco and polyester-covered stainless steel coils, detachable balloons, umbrella devices, covered stent polyvinyl alcohol particles, glue, and a combination of these instruments are mainly used in smaller CAVF. ${ }^{46,47}$

The Amplatzer (AGA Medical Corporation, Golden Valley, $\mathrm{MN}$ ) duct occluder is an ideal device for CAVF closure provided the drainage is large enough to allow the passage of the long sheath. 47

The efficacy of TCC is indisputable as various studies strongly support both the efficiency and safety of this technique. ${ }^{48-50}$

The cohort study of six patients by Harikrishnan et al revealed very encouraging results with the use of Cook (Cook Medical Inc., Bloomington, IN) coils (arterial approach) and Nitinol Ductal Occluders (venous approach). Complete closure of the fistulae was achieved in all patients. ${ }^{48}$

In accordance with these outcomes are the results of the retrospective study of 15 patients by Trehan et al, who reported $86.6 \%$ complete closure of the fistulae having used various occlusion devices: conventional metallic coils, floppy tips of coronary angioplasty guidewires, Amplatzer duct occlude, and Amplatzer septal occluder. ${ }^{49}$
Reidy et al recommend the TCC of CAVF as treatment of choice, after they showed its efficacy in their study. Satisfactory closure of the fistulae was observed in six of seven patients with the use of different embolization techniques, namely detachable balloon, coaxial embolization with platinum microcoils, a combination of detachable balloon and microcoil, and standard steel coils. In the unsuccessful case, the valve of the detachable balloon was damaged leading to early balloon deflation and a residual fistula. Importantly, there were no associated complications in any patient. ${ }^{50}$

In accordance with the opinion that TCC of CAVF should be the therapeutic strategy of choice are many more investigators, largely based on the success rates in various countries reported in the literature (87\% in India, 93\% in Russia, $87 \%$ in the United States, and $97 \%$ in the United Kingdom). ${ }^{13,51-54}$

\section{Surgical Treatment}

The surgical obliteration of the fistula by epicardial and endocardial ligations is the cornerstone of surgical treatment, first described by Biorck in 1947, and remains until now the most effective treatment. ${ }^{55}$

Gunnar Biorck and Clarence Crafoord performed the first successful surgical ligation of a pulmonary-to-coronary artery fistula on July 22, 1947, in Surgical Clinic I, at Sabbatsberg Hospital in Stockholm. The patient was a 15-year-old male adolescent with signs and symptoms suggesting a patent ductus arteriosus Botalli. He underwent left postero-lateral thoracotomy by the method of Crafoord with removal of the fifth rib. However, in the area of the ductus arteriosus no thrill was palpable and further exploration revealed an arteriovenous aneurysm on the pulmonary artery which was consistent with an arteriovenous communication between an aberrant branch of the left coronary artery and the pulmonary artery. ${ }^{55,56}$

Surgical treatment is generally reserved for single, large, symptomatic fistulae that are present with angina, cardiac decompression, or complications characterized by high-fistula flow, multiple communications, very tortuous pathways, multiple terminations, significant aneurysmal formation, or need for simultaneous distal bypass. $31,57,58$

Some authors have reported successful surgical occlusion of CAVF on beating heart off-pump. ${ }^{9,59}$ Ligation of the CAVF may be performed the outside the heart without cardiopulmonary bypass when there is a simple and easily accessible CAVF. ${ }^{4}$

Surgical techniques include internal closure of the fistula from within the pulmonary artery or a cardiac chamber, tangential arteriorhaphy for lateral fistulae, distal ligation alone, and proximal and distal ligations. Furthermore, if the coronary circulation has been compromised, ligation and coronary artery bypass grafting (CABG) is performed if necessary along with closure from within the aneurysmal coronary artery. Depending on the anatomical morphology of the fistula and the consequent involvement of the chambers, the most appropriate technique has to be chosen. ${ }^{8,15,60}$

Apart from the common postoperative complications (bleeding, infections, arrhythmias) postoperative myocardial ischemia may occur in the case of coronary ligation. For this 
reason intraoperative TOE is essential not only to review the occlusion or treatment of the fistula but also to assess properly the left and right ventricular function. In the case of significant abnormality of the left or right ventricular function, further intervention may be required with CABG surgery (on or off cardiopulmonary bypass). ${ }^{33}$

\section{Pharmacological}

Antianginal therapy addressing the demand and supply mismatch induced by the coronary "steal phenomenon" may be effective for symptom relief. ${ }^{57,61}$

Antiplatelet therapy and prophylactic precautions against bacterial endocarditis are highly recommended. ${ }^{31}$ In fact, standard endocarditis prophylaxis should be considered in all patients with CAVF regardless of the type of fistula present. $^{18}$

\section{Prognosis-Operative Risks}

In general, patients with CAVF who undergo a closure procedure have an excellent prognosis.

Recurrence rates are as small as 9 to $19 \%$ for TCC and 25\% in surgical ligation. ${ }^{51}$

The prognosis depends on the severity of the shunt and on certain complications that sometimes occur, such as heart failure, pulmonary hypertension, and bacterial endocarditis. $^{13}$

Furthermore, even though mortality related to the surgical procedure should remain extremely low, complications involving ischemic ST-changes, myocardial infarctions, arrhythmias, stroke, and recurrences of the fistulae or even failure of the surgical closure have also been reported. ${ }^{18}$

Early death can also rarely be the complication of TCC, as reported in the retrospective study by Alekyan et al, where a 4-year-old girl developed femoral artery thrombosis and acute renal failure. Other complications of this study included migration of the coil into the pulmonary artery, femoral artery thrombosis, and perforation of the vessel wall by the guidewire with immediate thrombosis and occlusion of the fistula. ${ }^{53}$

Said et al highlight the caution that should be given to perioperative myocardial infarction as it appeared to be a significant factor determining survival rates in their study. Out of the 46 patients that underwent surgical repair of their CAVF, 5 (11\%) patients developed postoperative myocardial infarction, showing the importance and relatively high incidence of this serious complication as well as the necessity for intraoperative TOE. ${ }^{62}$

After having reviewed individual cases and nonrandomized, observational cohorts of TCC, and surgical correction, Kiefer et al concluded that there are similar rates of residual fistula flow (20-30\%) during follow-up after the two techniques, hence, they appear to be equally effective. ${ }^{63}$

An important risk factor for postrepair adverse events was found to be drainage of the fistula into the coronary sinus, regardless of the intervention used (surgical or percutaneous). ${ }^{64,65}$
Arsmby et al, reviewed the surgical outcomes of 71 patients ( 81 fistulae), who ranged in age from 6 days to 77 years. There was only one operative death (1.4\%) and it was secondary to myocardial infarction. Other complications reported were arrhythmias (five patients), transient ischemic ECG changes (one patient) and stroke (one patient). Follow-up, which ranged from 0.1 to 21.1 years (longest mean 7.2 years), was available in 65 patients (all asymptomatic), and followup imaging studies in only 21 patients (angiography or echocardiography) with complete closure rates between 50 and $100 \%{ }^{13}$

The same authors reviewed the outcomes of TCC in 45 patients (range, 5 weeks-71 years) with a successful occlusion rate of $83 \%$. Recatheterization was required in one case whereas procedural complications included transient ischemic ECG changes (four patients), unretrieved device embolization to tricuspid valve or distal pulmonary artery (similar number), myocardial infarction (one patient), and transient atrial arrhythmia (one patient). There was only one procedure-related death (2.2\%) due to embolization of a coil to the left circumflex artery that led to left circumflex artery dissection. Follow-up (range, 1 day-4 years) in 42 of the patients showed no late complications and all were asymptomatic. Imaging studies (echocardiography and angiography) at follow-up (33 patients) revealed a complete closure of $91 \%{ }^{13}$

According to the ACC/AHA Guideline, echocardiography every 3 to 5 years may be useful for patients with small CAVF without clinical symptoms to exclude changes/progression of different parameters (size, chamber enlargement, new symptoms, arrhythmias) that may alter management approach (level of evidence: $\left.C^{*}\right){ }^{42}$

Furthermore, according to the same guidelines, intermediate- and long-term follow-up after repair with either surgery or TCC appears mandatory in cases where the patient still has large, patulous epicardial conduits. ${ }^{42}$

Long-term follow-up is essential because of the possibility of postoperative recanalization, persistent dilatation of the coronary artery and ostium, thrombus formation, calcification, arrhythmias, and myocardial infarction. ${ }^{16}$ In other studies where follow-up has been more detailed, small residual leaks following either type of procedure have been reported in approximately $10 \%$ of the patients. ${ }^{65}$ Patients should also receive antibiotic prophylaxis for any dental, gastrointestinal, or urologic procedure as they remain at risk for developing endocarditis until the flow is totally abolished. ${ }^{31}$

\section{Conclusion}

CAVF are rare anatomical conditions present in $0.002 \%$ of the general population comprising $48.7 \%$ of all coronary artery anomalies. Their mechanism of pathology lies upon the coronary "steal phenomenon" and they may be asymptomatic (usually small ones) or manifest with a variety of cardiac-

${ }^{*}$ Evidence level 4 (observational studies without controls) or extrapolations of level 2 (non-randomaized controlled trails) or 3 (observational studies with controls). 
related symptoms. The diagnostic approach includes angiography (main method used), echocardiography, and MDCT. Asymptomatic patients with small CAVF do not require immediate treatment and are managed with regular follow-up, whereas those with symptoms may be treated with either transcatheter approach or surgical ligation depending on the characteristics of the fistula. Both modes of treatment seem to be equally effective and their outcome is continuously assessed with long-term follow-up. The prognosis, which depends on the severity of the fistula, is excellent and the operative risks very low. Nevertheless, operative deaths as well as postoperative myocardial ischemia have been reported. Antibiotic prophylaxis should be given to patients undergoing any dental, gastrointestinal, or urologic procedure after the closure of the fistula until the blood flow is completely abolished for protection from endocarditis. Follow-up is essential as the patient needs to be regularly assessed for early diagnosis of recurrence of the fistula.

\section{References}

1 Ogden JA. Congenital anomalies of the coronary arteries. Am J Cardiol 1970;25(4):474-479

2 Krause W. Ueber den Ursprung einer akzessorischen A. coronaria aus der A. pulmonalis. Z Ratl Med 1865;24:225-229

3 Dimitrakakis G, Von Oppell U, Luckraz H, Groves P. Surgical repair of triple coronary-pulmonary artery fistulae with associated atrial septal defect and aortic valve regurgitation. Interact Cardiovasc Thorac Surg 2008;7(5):933-934

4 Ata Y, Turk T, Bicer M, Yalcin M, Ata F, Yavuz S. Coronary arteriovenous fistulas in the adults: natural history and management strategies. J Cardiothorac Surg 2009;4:62

5 Darwazah AK, Hussein IH, Hawari MH. Congenital circumflex coronary arteriovenous fistula with aneurysmal termination in the pulmonary artery. Tex Heart Inst J 2005;32(1):56-59, discussion 58-59

6 Dodge-Khatami A, Mavroudis C, Backer CL. Congenital Heart Surgery Nomenclature and Database Project: anomalies of the coronary arteries. Ann Thorac Surg 2000;69(4, Suppl)S270S297

7 Sakakibara S, Yokoyama M, Takao A, Nogi M, Gomi H. Coronary arteriovenous fistula. Nine operated cases. Am Heart J 1966;72 (3):307-314

8 Fernandes ED, Kadivar H, Hallman GL, Reul GJ, Ott DA, Cooley DA. Congenital malformations of the coronary arteries: the Texas Heart Institute experience. Ann Thorac Surg 1992;54(4):732-740

9 Olearchyk AS, Runk DM, Alavi M, Grosso MA. Congenital bilateral coronary-to-pulmonary artery fistulas. Ann Thorac Surg 1997;64 (1):233-235

10 Harris WO, Andrews JC, Nichols DA, Holmes DR Jr. Percutaneous transcatheter embolization of coronary arteriovenous fistulas. Mayo Clin Proc 1996;71(1):37-42

11 Schumacher G, Roithmaier A, Lorenz HP, et al. Congenital coronary artery fistula in infancy and childhood: diagnostic and therapeutic aspects. Thorac Cardiovasc Surg 1997;45(6):287-294

12 Carrel T, Tkebuchava T, Jenni R, Arbenz U, Turina M. Congenital coronary fistulas in children and adults: diagnosis, surgical technique and results. Cardiology 1996;87(4):325-330

13 Armsby LR, Keane JF, Sherwood MC, Forbess JM, Perry SB, Lock JE. Management of coronary artery fistulae. Patient selection and results of transcatheter closure. J Am Coll Cardiol 2002;39 (6):1026-1032
14 Kirklin JW, Barratt-Boyes BG. Congenital anomalies of the coronary arteries. In: Kirklin JW, Barratt-Boyes BG, eds. Cardiac Surgery. New York, NY: Churchill Livingstone; 1993:1167-1193

15 Bauer EP, Piepho A, Klövekorn WP. Coronary arteriovenous fistula: surgical correction of a rare form. Thorac Cardiovasc Surg 1994;42 (4):237-239

16 Gowda RM, Vasavada BC, Khan IA. Coronary artery fistulas: clinical and therapeutic considerations. Int J Cardiol 2006;107(1):7-10

17 Pelech AN. Coronary artery fistula. Available at: http://www. emedicine.com/ped/topic2505.htm. Accessed January 13, 2012

18 Latson LA. Coronary artery fistulas: how to manage them. Catheter Cardiovasc Interv 2007;70(1):110-116

19 Angelini P, Villason S, Chan AV, Diez JG. Normal and anomalous coronary arteries in humans. In: Angelini P, ed. Coronary Artery Anomalies. Philadelphia, PA: Lippincott Williams \& Wilkins; 1999:27-150

20 Qureshi SA. Coronary arterial fistulas. Orphanet J Rare Dis 2006;1 (51):51

21 Friedman AH, Fogel MA, Stephens P Jr, et al. Identification, imaging, functional assessment and management of congenital coronary arterial abnormalities in children. Cardiol Young 2007; 17(2, Suppl 2):56-67

22 Angelini P. Functionally significant versus intriguingly different coronary artery anatomy: anatomo-clinical correlations in coronary anomalies. G Ital Cardiol 1999;29(6):607-615

23 Juraschek SP, Kovell LC, Childers RE, Chow GV, Hirsch GA. Heart failure with transient left bundle branch block in the setting of left coronary fistula. Cardiol Res Pract 2011;2011:786287

24 Dursun A, Demirbag R, Yildiz A, Sezen Y, Altiparmak IH, Yilmaz R. Diagnosis of the left circumflex coronary artery fistula drainage into the left ventricle by echocardiographic color Doppler flow imaging. Int J Cardiol 2009;134(3):e85-e86

25 Shiga Y, Tsuchiya Y, Yahiro E, et al. Left main coronary trunk connecting into right atrium with an aneurysmal coronary artery fistula. Int J Cardiol 2008;123(2):e28-e30

26 Maleszka A, Kleikamp G, Minami K, Peterschröder A, Körfer R Giant coronary arteriovenous fistula. A case report and review of the literature. Z Kardiol 2005;94(1):38-43

27 Zenooz NA, Habibi R, Mammen L, Finn JP, Gilkeson RC. Coronary artery fistulas: CT findings. Radiographics 2009;29 (3):781-789

28 Taylor AJ, Rogan KM, Virmani R. Sudden cardiac death associated with isolated congenital coronary artery anomalies. J Am Coll Cardiol 1992;20(3):640-647

29 Androulakis A, Chrysohoou C, Barbetseas J, et al. Arteriovenous connection between the aorta and the coronary sinus through a giant fistulous right coronary artery. Hellenic J Cardiol 2008;49 (1):48-51

30 Rangasetty UC, Ahmad M. Giant coronary artery fistula with aneurysm and multiple openings: a two-dimensional echocardiographic evaluation. Echocardiography 2006;23(7):611-613

31 Said SA, Lam J, van der Werf T. Solitary coronary artery fistulas: a congenital anomaly in children and adults. A contemporary review. Congenit Heart Dis 2006;1(3):63-76

32 Angelini P. Coronary artery anomalies-current clinical issues: definitions, classification, incidence, clinical relevance, and treatment guidelines. Tex Heart Inst J 2002;29(4):271-278

33 Mahesh B, Navaratnarajah M, Mensah K, Amrani M. Treatment of high-output coronary artery fistula by off-pump coronary artery bypass grafting and ligation of fistula. Interact Cardiovasc Thorac Surg 2009;9(1):124-126

34 Dimitrakakis G, Wheeler R, Von Oppell U, et al. Surgical management of a double coronary cameral fistula associated with mitral and tricuspid regurgitation, patent foramen ovale, and chronic atrial fibrillation. Heart Surg Forum 2008;11(4): E209-E212 
35 Krishnamoorthy KM, Rao S. Transesophageal echocardiography for the diagnosis of coronary arteriovenous fistula. Int J Cardiol 2004;96(2):281-283

36 Lee CM, Leung TK, Wang HJ, Lee WH, Shen LK, Chen YY. Identification of a coronary-to-bronchial-artery communication with MDCT shows the diagnostic potential of this new technology: case report and review. J Thorac Imaging 2007;22(3):274-276

37 Dodd JD, Ferencik M, Liberthson RR, et al. Evaluation of efficacy of 64-slice multidetector computed tomography in patients with congenital coronary fistulas. J Comput Assist Tomogr 2008;32 (2):265-270

38 Srinivasan KG, Gaikwad A, Kannan BR, Ritesh K, Ushanandini KP. Congenital coronary artery anomalies: diagnosis with 64 slice multidetector row computed tomography coronary angiography: a singlecentre study. J Med Imaging Radiat Oncol 2008;52(2):148-154

39 Parga JR, Ikari NM, Bustamante LNP, Rochitte CE, de Avila LFR, Oliveira SA. Case report: MRI evaluation of congenital coronary artery fistulae. Br J Radiol 2004;77(918):508-511

40 Sibille L, Boudousq V, Soullier C, Rossi M, Mariano-Goulart D. Tc$99 \mathrm{~m}$ tetrofosmin SPECT in coronary cameral fistula. Clin Nucl Med 2009;34(7):473-474

41 Meissner A, Lins M, Herrmann G, Simon R. Multiple coronary artery-left ventricular fistulae: haemodynamic quantification by intracoronary Doppler ultrasound. Heart 1997;78(1):91-93

42 Warnes CA, Williams RG, Bashore TM, et al. ACC/AHA 2008 Guidelines for the Management of Adults with Congenital Heart Disease: Executive Summary: a report of the American College of Cardiology/American Heart Association Task Force on Practice Guidelines (writing committee to develop guidelines for the management of adults with congenital heart disease). Circulation 2008;118 (23):2395-2451

43 Collins N, Mehta R, Benson L, Horlick E. Percutaneous coronary artery fistula closure in adults: technical and procedural aspects. Catheter Cardiovasc Interv 2007;69(6):872-880

44 Reidy JF, Sowton E, Ross DN. Transcatheter occlusion of coronary to bronchial anastomosis by detachable balloon combined with coronary angioplasty at same procedure. Br Heart J 1983;49 (3):284-287

45 Perry SB, Rome J, Keane JF, Baim DS, Lock JE. Transcatheter closure of coronary artery fistulas. J Am Coll Cardiol 1992;20(1):205-209

46 Tacoy G, Ebinc H, Onal B, Abaci A, Ilgit E, Yalçin R. Congenitally severe tortuous circumflex artery fistula draining into the coronary sinus: transcatheter closure with Guglielmi detachable coils via different delivery system. J Cardiol 2009;54(2):317-321

47 Zhu XY, Zhang DZ, Han XM, et al. Transcatheter closure of congenital coronary artery fistulae: immediate and long-term follow-up results. Clin Cardiol 2009;32(9):506-512

48 Harikrishnan S, Bimal F, Ajithkumar V, et al. Percutaneous treatment of congenital coronary arteriovenous fistulas. J Interv Cardiol 2011;24(3):208-215
49 Trehan V, Yusuf J, Mukhopadhyay S, et al. Transcatheter closure of coronary artery fistulas. Indian Heart J 2004;56(2):132-139

50 Reidy JF, Anjos RT, Qureshi SA, Baker EJ, Tynan MJ. Transcatheter embolization in the treatment of coronary artery fistulas. J Am Coll Cardiol 1991;18(1):187-192

51 Said SA, Nijhuis RL, Op den Akker JW, et al. Diagnostic and therapeutic approach of congenital solitary coronary artery fistulas in adults: Dutch case series and review of literature. Neth Heart J 2011;19(4):183-191

52 Trehan V, Yusuf J, Mukhopadhyay S, et al. Transcatheter closure of coronary artery fistulas. Indian Heart J 2004;56(2):132-139

53 Alekyan BG, Podzolkov VP, Cárdenas CE. Transcatheter coil embolization of coronary artery fistula. Asian Cardiovasc Thorac Ann 2002;10(1):47-52

54 Qureshi SA, Tynan M. Catheter closure of coronary artery fistulas. J Interv Cardiol 2001;14(3):299-307

55 Biorck G, Crafoord C. Arteriovenous aneurysm on the pulmonary artery simulating patent ductus arteriosus botalli. Thorax 1947;2 (2):65-74

56 Dimitrakakis G, Challoumas D, Moschonas K, Dimitrakaki IA. eComment. Surgical management of coronary-to-pulmonary artery fistulas. Interact Cardiovasc Thorac Surg 2012;14(1): 104

57 Olgunturk R, Kula S, Tunaoglu FS. Transcatheter closure of a rare form of coronary arteriovenous fistula (circumflex artery to coronary sinus). Int J Cardiol 2006;113(2):261-263

58 Jung C, Jorns C, Huhta J. Doppler findings in a rare coronary artery fistula. Cardiovasc Ultrasound 2007;5:10

59 Hoendermis ES, Waterbolk TW, Willems TP, Zijlstra F. Large common left and right coronary artery to coronary sinus fistula. Interact Cardiovasc Thorac Surg 2006;5(6):788-789

60 Bauer HH, Allmendinger PD, Flaherty J, Owlia D, Rossi MA, Chen C. Congenital coronary arteriovenous fistula: spontaneous rupture and cardiac tamponade. Ann Thorac Surg 1996;62 (5):1521-1523

61 Bobos D, Chatzis AC, Giannopoulos NM, et al. Successful surgical repair of a giant arteriovenous fistula of the coronary arteries. J Card Surg 2006;21(3):269-270

62 Said SM, Burkhart HM, Schaff HV, et al. Late outcome of repair of congenital coronary artery fistulas-a word of caution. J Thorac Cardiovasc Surg 2013;145(2):455-460

63 Kiefer TL, Crowley AL, Jaggers J, Harrison JK. Coronary arteriovenous fistulae: the complexity of coronary artery-to-coronary sinus connections. Tex Heart Inst J 2012;39(2):218-222

64 Valente AM, Lock JE, Gauvreau K, et al. Predictors of long-term adverse outcomes in patients with congenital coronary artery fistulae. Circ Cardiovasc Interv 2010;3(2):134-139

65 Cheung DL, Au WK, Cheung HH, Chiu CS, Lee WT. Coronary artery fistulas: long-term results of surgical correction. Ann Thorac Surg 2001;71(1):190-195 